\title{
SYSTEM FOR COLLECTING AND RECYCLING OF USED BATTERIES AND ACUMULATORS
}

\author{
KRALIKOVA, R[uzena]; ANDREJIOVA, M[iriam]; WESSELY, E[mil] \& SOKOLOVA, H[ana]
}

\begin{abstract}
The contribution deals with collection and recycling of portable battery and accumulators. Potential risk for the environment, resulting from the great amount of used primary batteries represents a challenge for manufacturers, distributors, final consumers of batteries and most of all for those subjects, which are directly involved in collecting, processing and recycling of the used portable batteries and accumulators. The present state in Slovakia isn't suitable. The paper mentions possibilities of its solution by example from neighbouring region. This state is unfavourable as from look position of the state to European legislative and its strike (directive EU2006/66/ES) and producers and importers, who are responsible for performance of engagements.
\end{abstract}

Keywords: Recycling, collecting, primary batteries, waste, forecsting.

\section{INTRODUCTION}

The current state in the area of collecting and recycling batteries in Slovakia is not suitable. This situation is caused mainly by charging the battery manufacturers, while no indices and anticipations for systemic collection of used batteries from distribution spots, in terms of the waste act, are not being fulfilled. The same situation is also in the case of recycling, storage and disposal of these used batteries. This condition is unfavorable not only from the state's point of view and its attitude towards the EU legislation and its fulfilling (the new directiveEU2006/66/ES), but also for manufacturers or importers, who are directly responsible for putting the directive in practice. Therefore it is vital to search for the means of making the process of collecting more effective and find the solutions to this problem.

Considering the European legislative (directives 2006/66/ES), all the member states must reach a certain level of backwards collecting, processing and recycling of portable batteries. According to the directive, the level of collecting and subsequent recycling of used portable batteries and accumulators in the EU member states should reach the target of $25 \%$ by 2012 . This share should be at least $45 \%$ by 2016 . At the same time, the new directive forbids selling of batteries and accumulators which contain more than $0,0005 \%$ of mercury and portable batteries which contain more than $0,002 \%$ of cadmium. The forbiddance doesn't include the portable batteries used in emergency and alarm systems, medical appliances and wireless electronic appliances.

The target level of $45 \%$ of collecting is currently being reached only in Belgium and Switzerland, however very close to this number are the collective organizations in Austria, Germany and Netherland. Czech Republic is currently on the level of almost $17 \%$. Seeing that the situation in Slovakia is not satisfactory, it is necessary to create as good conditions as possible for successful fulfillment of mentioned goals of waste management in this particular area - used portable batteries and accumulators.

The directive assumes that financing of the costs of collecting, recycling and processing of all batteries must be secured by the manufacturers and importers of batteries in the Slovak Republic (SR). The separated collecting and recycling of industrial and automobile accumulators can be financed from the very good revenues gained by selling the obtained metals. Different situation is in the case of portable batteries, where the costs of collecting and processing significantly exceed the returns from recycling. The directive sets the compulsory recycling of all collected batteries and accumulators, which subsequently have to be materially capitalized.

\section{STATE IN SLOVAKIA}

Each year are imported to Slovakia about 550 tons of portable batteries and accumulators. This represents an enormous burden for environment, especially when amount that big isn't being suitably processed. Issue of this kind of waste is very current topic from several points of view: environmental, economic, law and technical (technological).

Collecting itself is a significantly complicated phase of the whole manipulation process with used portable batteries and accumulators. This particular phase still isn't completely solved, even in the countries which organize the collecting of used batteries for more than 10 years. The consequence of relatively low share of collected used batteries is the fact that many portable batteries finally end in an ordinary municipal waste. Possible material potential is being destroyed on dumping places and inincinerator plants. This material potential could be used to reach savings in drawing from primary natural resources etc. It is therefore necessary to collect and recycle as much used portable batteries and accumulators as possible. It is generally estimated, that maximal possible extent of recycling is approximately $80-85 \%$, because it is not possible to indentify the differential percentage of collected used portable batteries and accumulators, concerning their chemical 
composition. In countries where collecting of portable batteries is organized via collecting spots together with electro-waste, the level of collected amount is considered to be low, approximately $30 \%$ from the total presence in the particular country. Only the returned batteries can be collected and only those collected ones could be then sorted and recycled. The essential of this system is complexity beginning at the collecting stage and ending in the industrial usage of gained materials from used portable batteries and accumulators. Manipulating with used portable batteries and accumulators is a serious problem for every single state which won't be able to fulfill the conditions of the new European legislative, as well as for manufacturers and importers who are fully responsible for fulfillment of this legislative.

The act of Ministry of environment No 223/2001 Slovak Republic about wastes [6] is an implantation of the requirements set in the directive of European parliament and Council 2006/66/ES about batteries and accumulators and about waste batteries and accumulators $[5]$.

The current situation is mostly about charging the manufacturers. However, indices and assumptions for systemic collecting of used portable batteries are not being consistently fulfilled, especially in the case of collecting spots defined by law. We are talking mainly about distribution places defined by the mentioned law. These are the places where the new portable batteries and accumulators are being sold. Recycling, storage and material valuation or disposal are also defined and lacking practical effect. The sole recipient of the fees is currently the Recycling Fund of the Slovak Republic (RF), which:

- $\quad$ returns the fees for the collected and recycled batteries backwards or

- may grant the donations for projects concerning collecting and recycling, however there is no legal claim for these donations.

Based on the information from the European parliament, as well as considering the development in this area, the SAB SK (Slovak association for batteries) association was established in May 2006. Founders were the 7 most important manufacturers or importers of batteries in Slovak Republic. The goal of SAB SK is to represent the interests of manufacturers, importers and distributors of batteries at the legislative organs or other different institutions of the state administration, as well as to monitor the development in national and international legislation in this area. In cooperation with an international organization EPBA (European Portable Battery Association), the association aims to work out the strategic plans for reaching the maximum effect in facilitating backwards-collecting of the used batteries and their disposal or recycling in collaboration with authorized processor.

\section{TRENDS AND CONSUMPTION OF THE PRIMARY BATTERIES}

As it was mentioned earlier, the waste market with used portable batteries and accumulators in SR currently represents amount of 550 tons per calendar year. This number is crucial for setting the right collecting, processing and recycling capacities. Its size determines the possibility of creation as well as consequent usage of such capacities in SR or moving the collected and sorted used portable batteries and accumulators to recycling facility in abroad, with preference of the EU countries. The size of this waste market is currently being made of average consumption of portable batteries per SR citizen in amount of 4,8 batteries per year. Just for contrast and comparison of situation within EU we would like to mention, that the above indicator in the EU founding countries is in the range of $10-12$ batteries per citizen per year.

Aforesaid consumption consists of the two main categories, which are:

a. Primary batteries, mostly divided into:

- zinc - chloride batteries

- alkaline batteries

- lithium batteries, these however still represent only minimal share in the segment of primary batteries

b. Secondary batteries (accumulators)

Unit as well as weight proportion between the shares of primary and secondary batteries speak clearly about the dominance of primary batteries, in the rate $97 \%$ to $3 \%$. Based on this reality, the trend of development and consumption of the primary portable batteries in the recent years is a vital parameter for us. This parameter would identify potential running out of the development of consumption in the western European countries.

\subsection{Forecasting consumption of the primary batteries using exponential smoothing method}

The oldest method of time series modelling is the decomposition of time series. This method assumes that the time series can be divided into several independent components. Classical time series decomposition distinguishes four basic components: trend component $T_{t}$ (secular component), the seasonal component $S_{t}$, the cyclical component $C_{t}$ and irregular $I_{t}$ (residual component) component $[10,11]$.

The trend component is a major long-term development trend indicator value of the analysed time series and can occur in a linear or nonlinear form, it may be increasing, decreasing or constant. The seasonal component of a time series is defined as the regular periodic fluctuations around the trend line in one year or less. The cyclical component is defined as the fluctuations around a trend with irregular periods longer than one year. The irregular component is unpredictable. Every time series has some unpredictable component that makes it a random variable. 
These four components may be combined in different ways. It is usually assumed that they are multiplied or added:

- $\quad$ additive model assumes that all the components of the time series are independent of one another

$$
Y_{t}=T_{t}+S_{t}+C_{t}+I_{t}
$$

- multiplicative model assumes that all the four components are due to different cause but they are not necessarily independent

$$
Y_{t}=T_{t} \cdot S_{t} \cdot C_{t} \cdot I_{t}
$$

where $Y_{t}$ is observed value at time $t$.

There are several methods for selection of an appropriate model of the trend. To describe the trend component we can use analytical methods (resp. non adaptive methods). These methods try to describe the trend and an appropriate mathematical function based on the assumption that the model throughout the observed period changes. Adaptive methods steadily (adapting) adapt to changes in the nature of thetrend. The most famous adaptive methods include moving averages and exponential smoothing method. Other adaptive methods include the Box -Jenkins methodology.

Adaptive exponential smoothing methods allow a smoothing parameter to change over time, in order to adapt to changes in the characteristics of the time series. Exponential smoothing is a simple and pragmatic approach to forecasting, where by the forecast is constructed from an exponentially weighted average of past observations. This method is based on all previous observations, and their weight decreases towards the past, according to an exponential function. The older observation is theimpact on its future value is smaller, and gives it an exponentially decreasing weight.

Pegels [7] proposed taxonomy of exponential smoothing methods where each method has a trend component and a seasonal component. The all exponential smoothing methods are given in the following Table $1[8,9]$.

\begin{tabular}{|l|c|c|c|}
\hline \multirow{2}{*}{\begin{tabular}{c}
\multirow{2}{*}{$\begin{array}{c}\text { Trend } \\
\text { component }\end{array}$} \\
\cline { 2 - 4 }
\end{tabular}} & $\begin{array}{c}\boldsymbol{3} \\
\text { (none) }\end{array}$ & $\begin{array}{c}\boldsymbol{A} \\
\text { (additive) }\end{array}$ & $\begin{array}{c}\boldsymbol{M} \\
\text { (multiplicative) }\end{array}$ \\
\hline $\mathrm{N}$ (none) & $\mathrm{NN}$ & $\mathrm{NA}$ & $\mathrm{NM}$ \\
\hline $\mathrm{A}$ (additive) & $\mathrm{AN}$ & $\mathrm{AA}$ & $\mathrm{AM}$ \\
\hline $\begin{array}{l}\text { M } \\
\text { (multiplicative) }\end{array}$ & $\mathrm{MN}$ & $\mathrm{MA}$ & $\mathrm{MM}$ \\
\hline $\mathrm{D}$ (damped) & $\mathrm{DN}$ & $\mathrm{DA}$ & $\mathrm{DM}$ \\
\hline
\end{tabular}

Tab. 1. Models of exponential smoothing method

NN model describes the simple exponential smoothing method. AN model is Holt's exponential smoothing and the models of AA and AM are known as Holt-Winters exponential smoothing method. There are two possible models for each of the twelve methods: models with additive and multiplicative errors.
All twelve exponential smoothing methods can be written byusing the following form:

$$
\begin{gathered}
l_{t}=\alpha P_{t}+(1-\alpha) Q_{t}, \\
b_{t}=\beta R_{t}+(\phi-\beta) b_{t-1}, \\
s_{t}=\gamma T_{t}+(1-\gamma) s_{t-m},
\end{gathered}
$$

Where $l_{t}$ denotes the series level at time $t, b_{t}$ the trend (slope) at time $t, s_{t}$ the seasonal component of the series at time $\mathrm{t}, \mathrm{m}$ denotes the number of seasons in a year. The values $P_{t}, Q_{t}, R_{t}, T_{t}$ depended on the type of the method of smoothing. The Constants $\alpha, \beta, \gamma$ are from interval $(0,1)$. The constant $\phi$ are for damped trend form interval $\beta<\phi<1$, in other cases is equal to 1 .

The formulas for calculations the values $P_{t}, Q_{t}$, $R_{t}, T_{t}$ and points forecast for Holt'sexponential smoothing (AN model) and Holt-Winters exponential smoothing method (model AA and AM) are in the Table 2. The observed value in time $t$ is denoted by $Y_{t}$, forecast for $h$ periods is denoted by $F_{t+h}$ (Table 3$)$.

\begin{tabular}{|c|c|c|}
\hline \multicolumn{3}{|c|}{ Model } \\
\hline $\boldsymbol{A N}$ & $\boldsymbol{A A}$ & $\boldsymbol{A M}$ \\
\hline$P_{t}=Y_{t}$ & $P_{t}=Y_{t}-s_{t-m}$ & $P_{t}=Y_{t} / s_{t-m}$ \\
\hline$Q_{t}=l_{t-1}+b_{t-1}$ & $Q_{t}=l_{t-1}+b_{t-1}$ & $Q_{t}=l_{t-1}+b_{t-1}$ \\
\hline$R_{t}=l_{t-1}-l_{t-1}$ & $R_{t}=l_{t-1}-l_{t-1}$ & $R_{t}=l_{t-1}-l_{t-1}$ \\
\hline & $T_{t}=Y_{t}-Q_{t}$ & $T_{t}=Y_{t} / Q_{t}$ \\
\hline
\end{tabular}

Tab. 2. The formulas for AN, AA a nd AM model

\begin{tabular}{|c|c|}
\hline Model & Forecast \\
\hline $\boldsymbol{A N}$ & $F_{t+h}=l_{t}+h b_{t}$ \\
\hline $\boldsymbol{A} \boldsymbol{A}$ & $F_{t+h}=l_{t}+h b_{t}+s_{t+h-m}$ \\
\hline $\boldsymbol{A M}$ & $F_{t+h}=\left(l_{t}+h b_{t}\right) s_{t+h-m}$ \\
\hline
\end{tabular}

Tab. 3. The formulas for forecasting

For each method there are two models: model with additive and model with multiplicative errors. The model with additive errors is written as

$$
Y_{t}=\mu_{t}+\varepsilon_{t},
$$

the model with multiplicative errors is written as

$$
Y_{t}=\mu_{t}+\mu_{t} \varepsilon_{t}=\left(1+\mu_{t}\right) \varepsilon_{t} .
$$

For this research, the sale results of a distribution company, which operates in the whole Slovak Republic, were used. This company represents approximately $15 \%$ of the whole market with portable batteries and accumulators in SR, which makes our data exceptionally predicative. This predicative ability is supported by stable market shares of the distributed brands in SR, documented by the AC NIELSEN company, which in the long term monitors the mentioned segment.

For setting the trend of consumption theportable primary batteries, the sale data from years $2003-20010$ 
have been used. As a base data we used the sale results from the year 2003, to which we comparedsale results in the following years through the coefficient of growth, sale results in the following years. Basic describe statstics of the using data (mean, standard deviation SD, maximum or minimum value) are in Table 4 and Table 5.

\begin{tabular}{|c|c|c|c|c|}
\hline & \multicolumn{4}{|c|}{ Describestatistics (number of pieces) } \\
\hline Yaer & $\mathbf{2 0 0 3}$ & $\mathbf{2 0 0 4}$ & $\mathbf{2 0 0 5}$ & $\mathbf{2 0 0 6}$ \\
\hline Mean & 277077 & 254560 & 275932 & 282161 \\
\hline SD & 179,6125 & 194,0356 & 202,9561 & 197,8786 \\
\hline Max & 339535 & 348141 & 393770 & 395876 \\
\hline Min & 189907 & 202232 & 177562 & 211660 \\
\hline
\end{tabular}

Tab. 4. Describe statistics-primary batteries (2003-2006)

\begin{tabular}{|c|c|c|c|c|}
\hline & \multicolumn{4}{|c|}{ Describestatistics (number of pieces) } \\
\hline Yaer & $\mathbf{2 0 0 7}$ & $\mathbf{2 0 0 8}$ & $\mathbf{2 0 0 9}$ & $\mathbf{2 0 1 0}$ \\
\hline Mean & 305028 & 327354 & 312382 & 243365 \\
\hline SD & 231,3808 & 238,5135 & 279,6823 & 199,7236 \\
\hline Max & 413785 & 446090 & 589041 & 363033 \\
\hline Min & 225739 & 222431 & 171348 & 209401 \\
\hline
\end{tabular}

Tab. 5. Describe statistics-primary batteries (2007-2010)

We have to identify the type and model of time series and forecasts to determine a period of 36 months with using the open source R software package "forecast" [12]. The output from this software is the type of exponential model in the form of ETS (Error, Trend, Seasonal).

The analysis of output from the $\mathrm{R}$ package indicates that the most advantageous model is model without trend with additive seasonal component and multiplicative errors (MNA model). In this case a balancing constant $\alpha$ is equal to 0.1156 and the second constant $\gamma$ is equal to 0.0001 . The Figure 1 shows a graphical representation of empirical values together with the forecast values and the $80 \%$ and $90 \%$ confidence intervals.

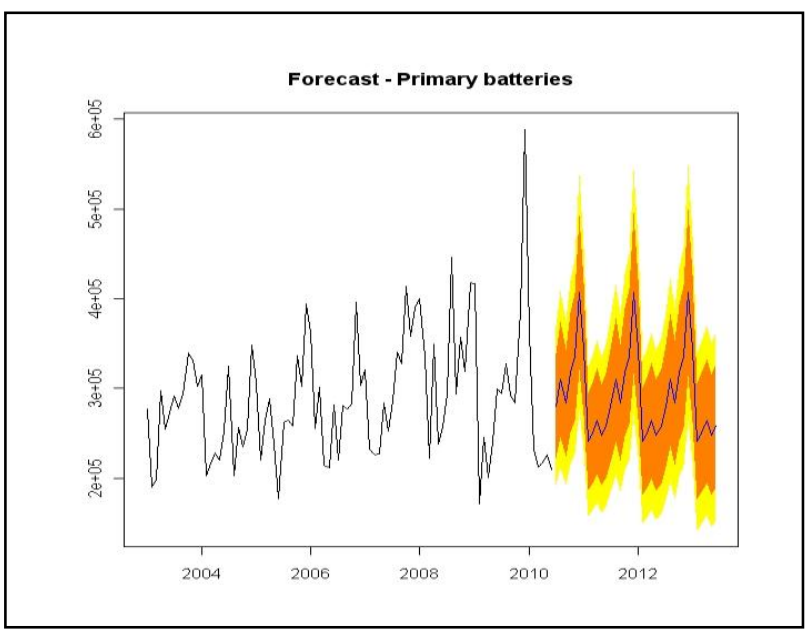

Fig. 1. Trend and forecast of consumption of the primary batteries in Slovakia

The forecast of consumption of the primary batteries confirms long-time evolution of a more or lesss table consumption maintains the constant level for last few years. If the evolution from 2004 showed little annual increasein consumption of primary portable batteries up to 2008 , the year 2008, with the advent of the global economic crisis year-on-year suspension growth with relatively sharp decrease in the consumption level of 2004 derogating from all growth development from that of 2004 .

Primary batteries are, as a whole, characterized by various size types of these batteries. As the carrying types in this category the following size types could be considered: AAA (or 3V), AA (or 6V), C (or 14V), D (or $20 \mathrm{~V}), 9 \mathrm{~V}$. From the creation of the consumption trend point of view, it is interesting to look at the mentioned tendency through the type marking. This trend is, for comparability, compared also to the base year 2003 through the coefficient of growth or decline in particular following year. This is graphically shown in the Figure 2.

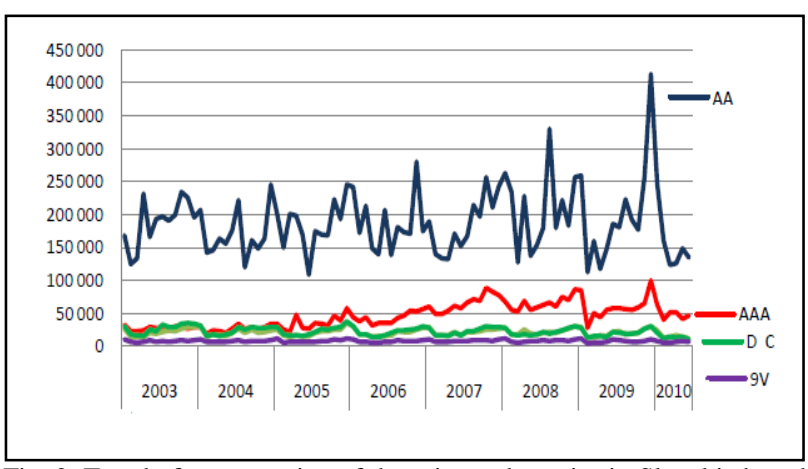

Fig. 2. Trend of consumption of the primary batteries in Slovakia based on the particular types

New technologies and a significant trend of miniaturization, more and more prefer a portable source of energy in the form of portable batteries size AA and AAA types whose represent the dominant share of consumption for several years.

The growth of overall consumption of the primary batteries was effected mainly by the growth of the AAA type, which is commonly used in modern appliances and which in fact represents the smallest portable primary unit from the mentioned basic group. Growth in the monitored term was more than double. Concerning the initial starting position of the AAA type in 2003 is, however, the impact on the overall trend of consumption of the primary batteries smaller than expected.

\section{CONCLUSION}

Potential risk for the environment, resulting from the great amount of used primary batteries represents a challenge for manufacturers, distributors, final consumers of batteries and most of all for those subjects, which are directly involved in collecting, processing and recycling of the used portable batteries and accumulators. Only the returned batteries can be collected, and only collected batteries can be then sorted and recycled. Evaluating of the primary and secondary portable batteries in Slovak Republic still lags behind the advanced European countries 


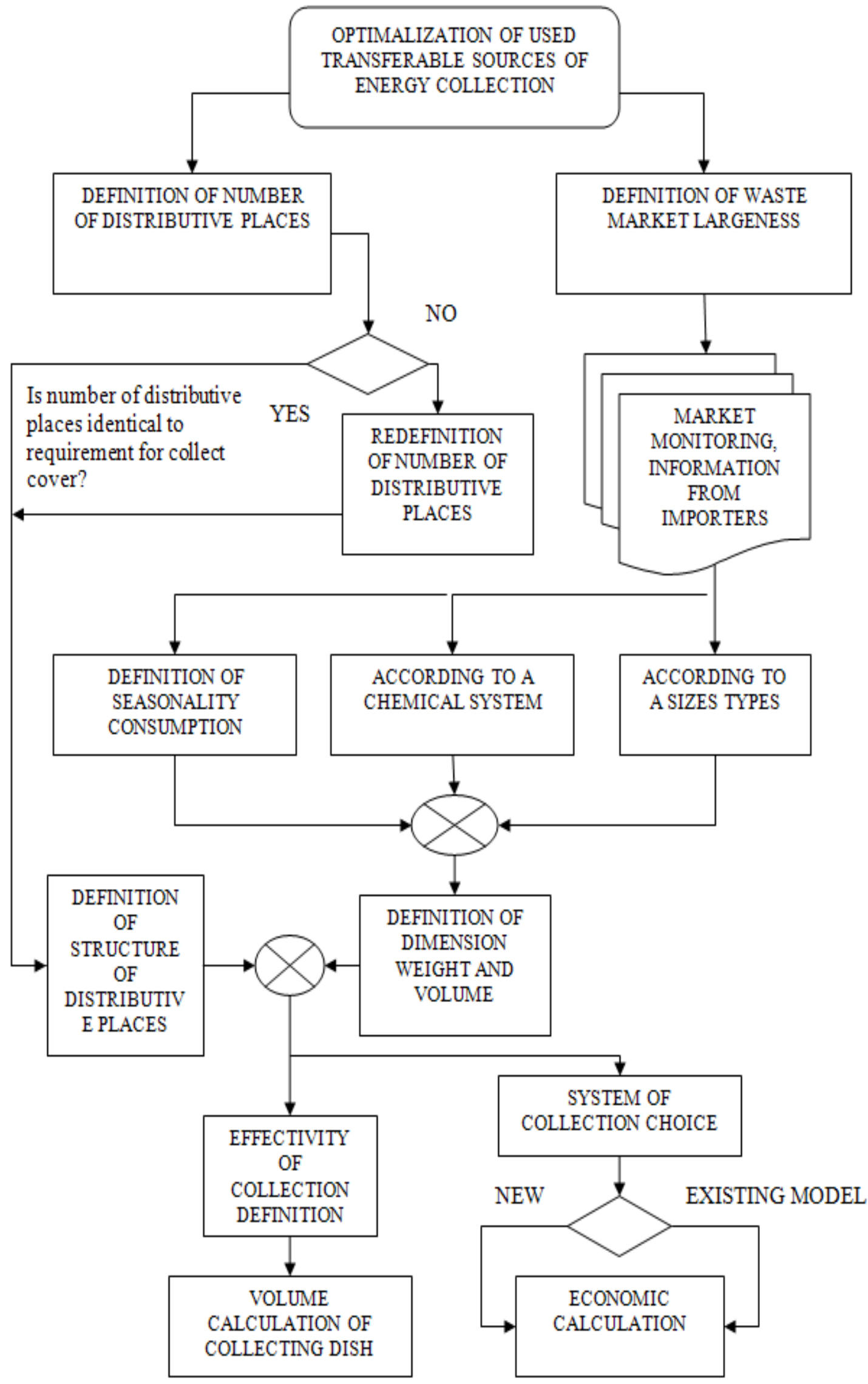


The basis of an effective system is complexity, since the collecting till the final industrial usage of gained materials from used portable batteries and accumulators.

Significantly high effectiveness is a matter of great interest of manufacturers and importers of the portable batteries in SR, because its cost greatly influences the process of price-making of the new portable batteries. Having that in mind, the most effective system will be successfully built by using their distribution capabilities, within the system of selling-collecting.

Analyzed knowledge, conclusions and methods was summarized to suggest methodology of collection optimization of used transferable germs and accumulators, see Figure 3. The most effective system will be successfully built by using their distribution capabilities, within the system of selling-collecting. This model presents optimal draft to effective settling of appropriate system of collection, processing, evaluation and recyclation of used portable batteries and accumulators regarding to current legislation. If there would be any change in the legislation, we can make corrections in the process of parameters of the whole system consecutive definition, what won't affect algorithm that was suggested.

Considering the trend of consumption development of the portable primary batteries and accumulators in SR, it is not possible to anticipate significantly rapid growth of the waste market in this area. On the contrary, it is possible to expect balanced, slightly increasing unit consumption, which is the input assumption for the consequent solution and optimalization of the collecting, processing and recycling capacities (concerning the measure of technical and logistic facilitating).

It will be necessary to minutely evaluate the particular trends which influence the unit consumption, because the increase of the unit consumption of the smallest types and decrease of consumption of the biggest types could eventually cause dimensional decrease of size of the waste market of the particular category in weight units.

\section{ACKNOWLEDGEMENTS}

This contribution was worked - out frame within the frame project No 032TUKE-4/2012 „ICT aided new forms of learning and increasing the efficiency of education for environmental study programs".

\section{REFERENCES}

[1] Hohn, B. (2002). Modern Gear Calculation. Proceedings of the International Conference on Gears, Munich, VDI-Berichte, ISSN 1429-6055, pp. 23-43

[2] Council Directive 91/157/EEC of 18 March 1991 on batteries and accumulators containing certain dange-rous substances, Official Journal L 078, 26/03/1991

[3] Legislative resolution on the proposal for a decision of the 91/157/EEC (5694/5/2005-C6-0268/2005-2003/0282(COD)), European Parliament, Brussels

[4] Commission directive 98/101/EC adapting to technical progress Council Directive 91/157/EEC on batteries and accumulators containing certain dangerous substances

[5] Directive 2006/66/EC on batteries and accumulators and waste batteries and accumulators as regards placing batteries and accumulators on the market

[6] Slovak directive No 386/2009 SR amending and supplementing no. 223/2001 about waste

[7] Pegels, C.C. (1996). Exponential forecasting: some new variations. Management Science, Vol.15,No. 5,1996, pp. 311-315.

[8] Hyndman, R.J.; Koehler, A.B.; Snyder, R.D.; Grose, S. (2002). A state space framework for automatic forecasting using exponential smoothing methods. Available from: http://www.forecasters.org/pdfs/ijf/HKSG.pdf. Accessed on: 2012-07-04

[9] Hyndman. R.J. (2008): Time series and forecasting in R Available from: http://wwwmaths.anu.edu.au. Accessed on: 201207-04

[10] Rublíková, E. (2007). Analýza časových radov. Iura Edition, ISBN 978-80-10-01364-7, Bratislava

[11] Hudec, O. Sisáková,J.; Rataová,A; Želinksý,T. (2007). Štatistické metódy v ekonomických vedách. Elfa, s.r.o., ISBN 978-80-8086059-2, Košice

[12] Hyndman, R.J.; Razbash,S.; Schmidt, D. (2012): Forecasting functions for time series and linear models. Available from http://cran.r-project.org/web/packages/forecast/forecast.pdf. Accessed on: 2012-07-04 